\title{
Maturation of the response of human fetal pancreatic explants to glucose
}

\author{
B. E. Tuch, A. Jones and J. R. Turtle \\ Department of Medicine, The University of Sydney, Sydney, NSW, Australia
}

\begin{abstract}
Summary. The release of insulin from the human pancreas in response to glucose is known to be either poor or absent in the fetus, whereas in the infant and adult, the response is much greater. The maturation of this response was examined systematically in this study using pancreases that were initially obtained at 14-20 weeks gestation and maintained either in culture alone or by passaging them in diabetic nude mice. Stimulation with glucose was carried out in vitro using tissue of ages ranging from 14 to 58 weeks. A response to glucose was initially seen at 25 weeks and this dramatically increased
\end{abstract}

in the fetal tissue that had reached an age of 55 weeks or more. One of the nude mice used for passage developed normoglycaemia and when the pancreatic implant of age 52 weeks was removed, diabetes recurred. Our findings support the idea of the use of human fetal pancreatic tissue in the treatment of diabetes mellitus.

Key words: Human fetal pancreas, fetal development, nude mouse, glucose stimulation, xenografts, tissue culture, diabetes.
Human fetal pancreas responds poorly to a glucose stimulus both in vitro $[1,2]$ and in vivo $[3,4]$. The reason for this is unknown. It is not the lack of ability of the islets to produce insulin per se, because pancreatic tissue in vitro releases insulin in response to stimulation with theophylline [2] and ions such as barium and potassium [5]. It is known that the ability of the pancreas to respond to glucose is sluggish at birth for full-term infants $[6,7]$ and improves in a matter of $24 \mathrm{~h}$ after birth [7]. A similar initial sluggish response is seen with pre-term infants and does not improve within days after birth $[7,8]$. It is not until at least 1 month and, possibly 6 months of age, that a maximal response to glucose occurs in these infants [9].

The maturation process of the response to glucose by the endocrine pancreas has not been studied systematically in man. We wish to report our experience in monitoring this maturation process using human fetal tissue in vitro.

\section{Materials and methods}

\section{Materials}

Fetal pancreatic tissue was obtained following the therapeutic termination of pregnancies by evacuation-curette or prostaglandin-induction between 14 and 20 weeks gestation. The tissue was divided into $1 \mathrm{~mm}^{3}$ explants and cultured as previously described at an air liquid interface [2]. The medium used was RPMI 1640, containing glucose $(11.1 \mathrm{mmol} / \mathrm{l})$ and Hepes buffer $(20 \mathrm{mmol} / 1)$, and was supplemented with $10 \%$ minimum essential medium (modified) amino-acid solution $(\times 50)$ without L-glutamine (Flow Laboratories, McLean, Virginia, USA), $6 \%$ L-glutamine $(200 \mathrm{mmol} / 1)$, $4 \%$ human stable plasma protein solution (equivalent to $0.2 \%$ plasma protein), penicillin $(50 \mu \mathrm{g} /$ $\mathrm{ml})$ and gentamicin $(50 \mu \mathrm{g} / \mathrm{ml})$. Tissue culture medium was changed three times per week and the medium assayed for insulin released to confirm viability of the tissue. Most of the fetal pancreases obtained were viable initially in tissue culture, only $13 \%$ either not maintaining their ability to secrete insulin or becoming infected.

Prolonged culturing of these pancreatic explants was carried out as long as possible up to a maximum of 95 days, although there was a steady drop-out rate because of infection or failure to secrete insulin into the culture medium at a steady rate $(<0.1 \mathrm{mU} /$ plate of five explants per day). The response to glucose by fetal pancreatic explants maintained for a longer period of time was made possible by passaging a different series of explants implanted in diabetic nude mouse [10]. Diabetic rather than non-diabetic mice were chosen because of the added advantage of testing the efficacy of the explants in vivo.

The nude mice were kept in a semi-sterile environment, removed from other animals. They were rendered diabetic with intraperitoneal streptozotocin at an initial dose of $220-275 \mathrm{mg} / \mathrm{kg}$ body weight and, if necessary, a supplementary dose of up to $320 \mathrm{mg} / \mathrm{kg}$. Plasma glucose was measured in blood taken from the tail vein, using a glucose oxidase technique (Yellow Springs Instrument, Model No.23AM, Yellow Springs, Ohio, USA). Oral glucose tolerance tests were carried out on both experimental and control animals fasted overnight using an empirical concentration of $1 \mathrm{mg} / \mathrm{g}$ of glucose in a volume $<0.3 \mathrm{ml}$ administered intragastrically through clear vinyl tubing (outer diameter $0.96 \mathrm{~mm}$, inner diameter $0.58 \mathrm{~mm}$ ). Blood was collected from the tail vein at the time of administration of the glucose and 20 and $60 \mathrm{~min}$ later. 
Table 1. Blood glucose values of the diabetic nude mice before and after subcutaneous implantation of human fetal pancreatic explants

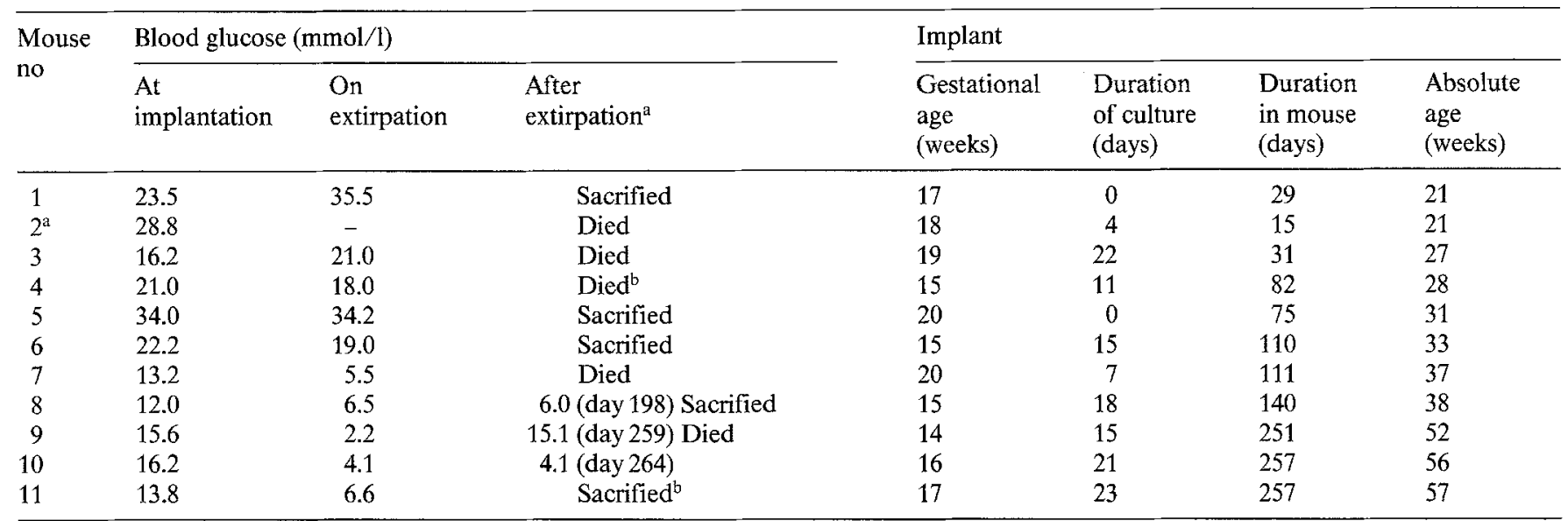

a This animal received the explants intraperitoneally;

${ }^{\mathrm{b}}$ Chronically sick. Times mentioned represent period after the initial implantation in the mouse

Table 2. Effect of stimulation with glucose $(20 \mathrm{mmol} / \mathrm{l})$ of human fetal pancreatic explants cultured alone or after passage in the nude mouse

\begin{tabular}{|c|c|c|}
\hline $\begin{array}{l}\text { Absolute age } \\
\text { of pancreas } \\
\text { (weeks) }\end{array}$ & Cultured alone & $\begin{array}{l}\text { Cultured after } \\
\text { passage in nude } \\
\text { mouse }^{a}\end{array}$ \\
\hline $10-14$ & $1.04 \pm 0.10(n=3)$ & - \\
\hline $15-19$ & $0.97 \pm 0.07(n=23)$ & - \\
\hline $20-24$ & $1.03 \pm 0.15(n=15)$ & $0.81 \pm 0.16(n=2)$ \\
\hline $25-29^{b}$ & $1.32 \pm 0.39(n=4)$ & $1.57 \pm 0.24(n=6)$ \\
\hline $30-34$ & $1.53 \quad(n=1)$ & $1.39 \pm 0.31(n=3)$ \\
\hline $35-39$ & - & $1.21 \pm 0.14(n=8)$ \\
\hline $40-44$ & - & $1.50 \quad(n=1)$ \\
\hline $50-54$ & - & $1.65 \pm 0.42(n=2)$ \\
\hline $55-59^{c}$ & - & $2.92 \pm 0.43(n=6)$ \\
\hline
\end{tabular}

Values are expressed as the ratio of insulin release during the stimulation phase with that during a non-stimulation period of similar duration. 'a Significant differences found only between 55-59 week age group and 20-24 weeks, by analysis of variance, with variances normalized by use of logarithmic values, and Duncan's multiple-range test $(p=0.0013)$. ${ }^{\mathrm{b}}$ The ratio of insulin release during the period 25-59 weeks was significantly higher than that for tissue younger than 25 weeks ( $\mathrm{p}=0.0000$; by analysis of variance with variances normalized by use of reciprocal values). ${ }^{\mathrm{c}}$ Within the period $25-59$ weeks the ratio of insulin release in tissue 55 weeks or older was significantly greater than that for the younger tissue $(p=0.0002$; by analysis of variance with variances normalized by use of logarithmic values)

\section{Stimulation of explants in vitro}

On the afternoon of the day before stimulation of the explants, the culture medium was changed to one that had the same contents as before, except for the deletion of the modified amino-acid solution $(\times 50)$. On the day of stimulation, this medium was replaced with Dulbecco's phosphate-buffered saline supplemented with $4 \%$ human stable plasma protein solution, Hepes buffer $(20 \mathrm{mmol} / \mathrm{l})$ and glucose $(2.8 \mathrm{mmol} / \mathrm{l})$. The explants were allowed to bathe in this basal medium at $\mathrm{pH} 7.4$ for three periods of 1.5 -h duration each to stabilize the basal secretion of insulin. A fourth 1.5 -h period made no significant difference to the secretion of insulin. The phase of stimulation with glucose $(20 \mathrm{mmol} / \mathrm{l})$, made up in basal medium, immediately followed the third basal period and lasted $1.5 \mathrm{~h}$. At the conclusion of this period, the experiment was complete and the explants were re-incubated with standard culture medium. The insulin concentration of the medium removed after both the period of stimulation and the third basal period was measured by radioimmunoassay and the absolute amount determined by multiplying this value by the volume of medium removed from the culture plates. A ratio was subsequently obtained expressing the amount of insulin released into the medium during the stimulation phase to that released during the immediate preceding basal phase. A value of one theoretically represented no stimulation.

\section{Implantation of explants into nude mice}

Either uncultured human fetal pancreatic explants or those cultured for up to 23 days (median 15 days) were transplanted subcutaneously into the iliac fossa of 10 diabetic nude mice and intraperitoneally in one animal (Table 1). Cultured explants were used in most cases to mimic the clinical situation for diabetic patients where explants would be cultured in an attempt to reduce immunogenicity before being implanted. The explants from one pancreas only were used in each nude mouse. Between 15 and 257 days after transplantation, the implants were removed from the animals. Four of the animals died several hours before removal of the tissue and four were sacrified because of infection. The remaining three were kept alive thereafter. This tissue was divided into $1 \mathrm{~mm}^{3}$ fragments and re-cultured in vitro before being exposed to glucose $(20 \mathrm{mmol} / 1)$ during a period of static incubation. Stimulation with glucose was repeated at intermittent intervals for as long as the explants continued to release insulin into the culture medium at a steady rate (maximum 64 days).

Whenever the age or absolute age of pancreatic tissue is mentioned, it refers to the age at which termination of pregnancy occurred plus the duration of time the explants have remained both in culture and in the nude mice.

\section{Statistical analysis}

Of the statistical tests used, analysis of variance and regression were carried out on a digital 1170 computer using appropriate BMDP programs. Duncan's multiple range test was performed as a supplement to the results of analysis of variance. Student's t-test was used to test the null hypothesis.

\section{Results}

The results of glucose stimulation of fetal pancreatic explants either cultured alone or passaged in the nude mouse and then cultured are shown in Table 2. Re- 


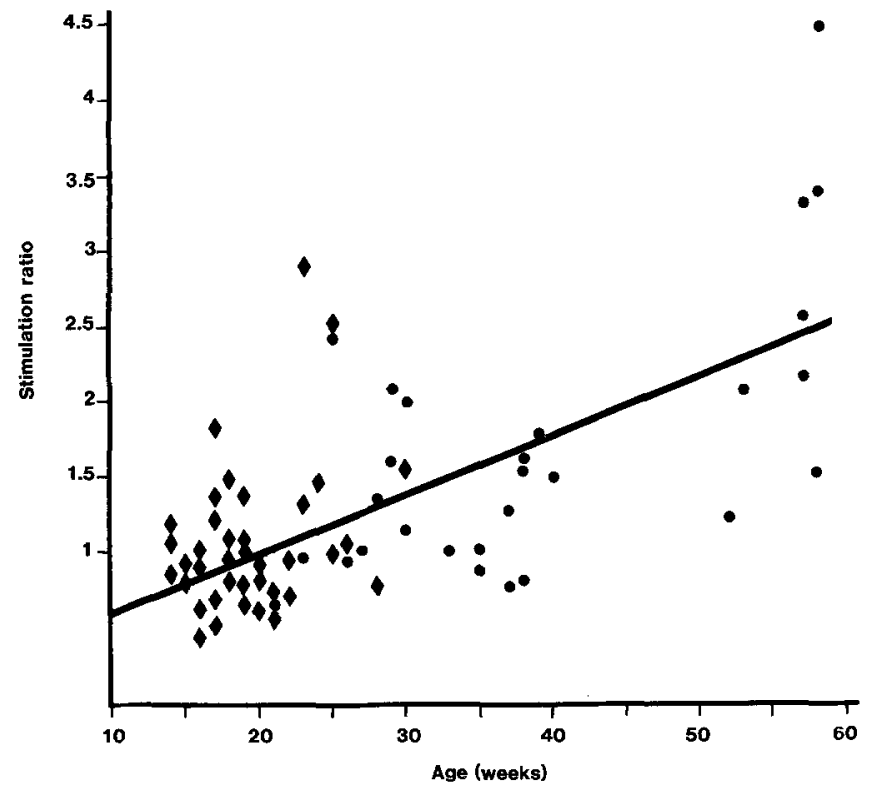

Fig.1. Relationship between absolute age of fetal pancreas and response to glucose (expressed as ratio of insulin released in stimulation phase to that released in non-stimulation phase). Values obtained from tissue passaged in nude mice; values obtained from tissue cultured alone. The correlation ratio was $0.65(p<0.001)$ and the relationship expressed by the straight line in the figure $(y=0.24+0.04 \times)$

sponse to glucose began to occur after an absolute age of 25 weeks for both tissue cultured alone and that passaged in the nude mouse. This difference in response reached significant levels when the numbers were increased by combining the two groups ( $p=0.000$, with variances normalized by use of reciprocal values). The response to glucose continued thereafter with a dramatic increase after 55 weeks ( $p=0.0002$ with variances normalized by use of logarithmic values), a time corresponding to a post-gestational age of 15 weeks.

Overall there was a significant relationship between absolute age and the stimulation ratio (Fig. 1, $r=0.65$; $p<0.001$ ). There was no significant correlation between age and the amount of insulin released into the medium during the non-stimulation period $(r=0.06)$, thus excluding a baseline shift downwards with advancing age as the reason for the increase in the ratio. Theoretically proteolytic activity during the stimulation phase of the older pancreases could also increase the ratio by degrading the insulin tracer during radioimmunoassay and causing an apparent increase in insulin. This possibility was excluded by showing $100 \%$ recovery of the tracer after incubation with medium from the stimulation phase and precipitation with $10 \%$ trichloroacetic acid, compared with controls $(86.8 \pm 1.5 \%$ versus $86.9 \pm 4.8 \%$; mean \pm SD). The relationship between age and the stimulation ratio also reached significance for the tissue passaged through the nude mouse with an age range of $21-58$ weeks $(r=0.64 ; p<0.001)$, but not for the tissue cultured alone, which had an age range of 14-30 weeks.
For the tissue removed from the nude mouse and maintained in culture for as long as it was viable, two sets of stimulation ratios are available. An initial value in response to glucose was obtained from implants removed from the nude mice and placed in culture and subsequent values were measured during the remaining time the tissue was cultured (Table 2). For the initial stimulation, the relationship between the stimulation ratio and absolute age of the pancreas was described by the formula: ratio $=0.047 \times$ age -0.37 . The differences between the observed ratio for subsequent stimulation and the expected values for tissue of the relevant ages, based on this formula, were analysed by Student's t-test and found to be significantly different from zero (null hypothesis) at $p<0.05$, that is, the observed ratio for subsequent stimulations of tissue passaged in the nude mice was significantly higher than expected from the above formula.

The mean \pm SEM non-fasting blood glucose level of the mice at transplantation was $19.35 \pm 2.25 \mathrm{mmol} / 1$ (Table 1). At the time the tissue was removed from the animals for re-culture, five mice had non-fasting blood glucose values of $4.4 \pm 0.66 \mathrm{mmol} / 1$ and oral glucose tolerance tests $(0 \mathrm{~min}: 3.88 \pm 0.76 \mathrm{mmol} / 1 ; 20 \mathrm{~min}$ : $11.78 \pm 1.84 \mathrm{mmol} / 1$; and $60 \mathrm{~min}: 4.28 \pm 0.76 \mathrm{mmol} / \mathrm{l})$ that were within our normal range $(0 \mathrm{~min}: 6.40 \pm$ $0.49 \mathrm{mmol} / 1 ; 20 \mathrm{~min}: 11.78 \pm 0.85 \mathrm{mmol} / 1 ; 60 \mathrm{~min}$ : $7.13 \pm 0.47 \mathrm{mmol} / 1 ; n=18)$. The age of the pancreases in these animals ranged from 37 to 57 weeks. Three of the mice were subsequently kept alive. One of them became diabetic again, rapidly lost weight ( $20 \mathrm{~g}$ down to $12 \mathrm{~g}$ ) and died 8 days after removal of the implant (age 52 weeks). The non-fasting blood glucose level in that mouse before death was $15.1 \mathrm{mmol} / 1$ and the glucose tolerance test abnormal with the $60 \mathrm{~min}$ glucose value the same as the $20 \mathrm{~min}$ one $(0 \mathrm{~min}: 7.1 \mathrm{mmol} / 1 ; 20 \mathrm{~min}$ : $14.6 \mathrm{mmol} / 1$; $60 \mathrm{~min}: 14.5 \mathrm{mmol} / 1)$.

\section{Discussion}

These results show that the response of human fetal pancreatic tissue to glucose matures over a period of many months, corresponding to a time span from early in the second trimester of fetal life to 15 weeks after the birth of an infant. Our findings are similar to those reported in the clinical situation with no release of insulin in response to glucose before 25 weeks of age [3, 4], sluggish release of insulin in both pre-term and terminfants [6-8], and a doubling of the insulinogenic response to glucose between 1 and 6 months of age [9]. A similar time-dependent maturation of response to glucose has also been recorded in animals, especially the fetal rat [11], and in pancreatic tissue removed from the fetal rat and cultured in vitro [12-13].

It is possible that the maturation of the response to glucose in these experiments represents the reaction of $\mathrm{B}$ cells to the hyperglycaemic environment of both the 
diabetic nude mouse and the culture system, rather than a process of physiological maturation. This would be consistent with the enhanced response to glucose of B cells in the fetus of both diabetic pregnant women [6] and animals [14]. It is unlikely that the process of maturation was due to the environment in the nude mouse itself. First, the beginning of the response to glucose was seen at the same time in tissue cultured alone and that passaged through the nude mouse (Table 2). Second, the initial stimulation ratios for tissue removed from the mice were significantly less than those expected, based on subsequent stimulation ratios obtained by further culturing of the same tissue. If the internal environment of the nude mouse was responsible for maturation of the tissue, the reverse would have been more likely. The contribution of the high glucose concentration $(11.1 \mathrm{mmol} / 1)$ in the culture medium to the maturation of the response to glucose was not examined in this study, culturing of explants in a medium with a low glucose concentration being required for this purpose.

The enhancement in response to glucose seen in vitro was reflected in vivo in one diabetic nude mouse. The cultured explants from a single fetal pancreas were able to reverse the diabetes induced in this animal after several months of implantation. Removal of the tissue caused a recurrence of the diabetes, thus excluding regeneration/recovery of mouse islets as the cause of the amelioration. This latter reason was the most likely explanation for the normoglycaemia found at the time of removal of the implants in two other mice.

The ability of pancreatic tissue from the human fetus to reverse diabetes in the nude mouse is consistent with the numerous reports of the efficacy of fetal pancreatic tissue from animals to reverse streptozotocin-induced diabetes $[15,16]$. This finding supports the idea that the human fetal pancreas may be a source of tissue for transplantation into insulin-dependent diabetic man. Provided rejection does not occur, the data suggest that at least several months will have to elapse before responsiveness to glucose can be expected.

Acknowledgement. We wish to thank Dr. I.D. Caterson for his critical appraisal of this manuscript and Ms. M. Pranckunas and Miss L. Gillman for their typing of it. This work was supported by the National Health and Medical Research Council of Australia.

\section{References}

1. Milner RDG, Ashworth MA, Barson AJ (1972) Insulin release from human fetal pancreas in response to glucose, leucine and arginine. J Endocrinol 52: 497-505

2. Maitland JE, Parry DG, Turtle JR (1980) Perifusion and culture of human fetal pancreas. Diabetes 29 (Suppl 1):57-63

3. Adam PAJ, Teramo K, Raiha N, Gitlin D, Schwartz R (1969) Human fetal insulin metabolism early in gestation: response to acute elevation of the fetal glucose concentration and placental transfer of human insulin- $\mathrm{I}^{131}$. Diabetes 18: 409-416

4. Thorell JI (1970) Plasma insulin levels in normal human fetuses. Acta Endocrinol (Copenh) 63: 134-140

5. Milner RDG, Barson AJ, Ashworth MA (1971) Human fetal pancreatic secretion in response to ionic and other stimuli. J Endocrinol 51: 323-332

6. Baird JD, Farquhar JW (1962) Insulin-secreting capacity in newborn infants of normal and diabetic women. Lancet 1: 71-74

7. Grasso S, Fallucca F, Mazzone D, Giangrande L, Romeo MG, Reitano $G$ (1983) Inhibition of glucagon secretion in the human newborn by glucose infusion. Diabetes 32: 489-492

8. Grasso S, Distefano G, Messina A, Vigo R, Reitano G (1975) Effect of glucose priming on insulin response in the premature infant. Diabetes 24: 291-294

9. Von Euler V, Larsson Y, Persson B (1964) Glucose tolerance in the neonatal period and during the first six months of life. Arch Dis Child 39:393-396

10. Tuch BE, Ng ABP, Jones A, Turtle JR, Caterson ID (1984) Transplantation of human fetal pancreatic tissue into diabetic nude mice. Transplant Proc 16: 1059-1061

11. Kervran A, Girard JR (1974) Glucose-induced increase of plasma insulin in the rat foetus in utero. J Endocrinol 64: 545-551

12. Heinze E, Schatz H, Nierle C, Pfeiffer EF (1975) Insulin biosynthesis in isolated pancreatic islets of fetal and newborn rats. Diabetes $24: 373-377$

13. Hellerström C, Lewis NJ, Borg H, Johnson R, Freinkel N (1979) Method for large-scale isolation of pancreatic islets by tissue culture of fetal rat pancreas. Diabetes 28: 769-776

14. Kervran A, Guillaume M, Jost A (1978) The endocrine pancreas of the fetus from diabetic pregnant rat. Diabetologia 15:387-393

15. Brown J, Heininger D, Kuret J, Mullen Y (1981) Islet cells grow after transplantation of fetal pancreas and control of diabetes. Diabetes 30: 9-13

16. Hoffman L, Mandel TE, Carter W (1982) Insulin content of fetal mouse pancreas in organ culture and after transplantation. Diabetes 31: $826-829$

Received: 4 May 1984

and in revised form: 6 November 1984

Dr. B.E. Tuch

Department of Medicine

University of Sydney

Sydney, NSW

Australia 2006 